\title{
Featural definition of syntactic positions: Evidence from hyper-raising
}

\author{
Suzana Fong*
}

\begin{abstract}
Hyper-raising consists in raising the subject of an embedded finite clause into the embedding clause. This introduces a challenge to the PIC. To circumvent this problem, I follow van Urk (2015)'s featural definition of syntactic positions. I propose that the COMP in HR has A-features (i.e. features that create A-positions). These features trigger the movement of the subject to Spec-CP. Being at a phase edge, the embedded subject is accessible to a matrix probe. The postulation of features in COMP will be argued for by Mongolian data, where the embedded subject can receive ACC case while remaining in the finite embedded clause. I call this variety of HR 'medialraising'. In a canonical sentence, if the embedded NOM subject contains a locallybound reflexive, the reflexive cannot be bound by the matrix subject. However, in medial-raising, binding is possible. Spec-CP is a position that can account for these properties: it is still inside the embedded clause, but it extends the binding domain of the medial-raised subject. If this analysis is correct, still following van Urk (2015), we may predict that there is an instance of HR that is triggered by a composite $\mathrm{A} / \overline{\mathrm{A}}$ probe in COMP. I analyze data from Kipsigis as this type of HR, where it seems that a lower argument can hyper-raise across the subject. If this lower argument bears the features that the composite probe in COMP is looking for, but the subject does not, the object will be targeted for HR.
\end{abstract}

Keywords. hyper-raising, PIC, featural definition of syntactic positions, $\mathrm{A} / \overline{\mathrm{A}}$ distinction, accusative subjects, Mongolian

1. Introduction. 'Hyper-raising' (HR) describes a biclausal sentence where the embedded clause is finite, but which a DP, typically the subject, raises from. HR differs from the standard variety of raising to subject and from ECM/object shift. In both these constructions, the embedded clause is infinitival. As such, the subject cannot be licensed there and raises into the matrix clause to be assigned case. Standard raising to subject is illustrated below with English examples.

a. Mary is likely [ $t$ to have bought a new car ].

b. The cat seems [ $t$ to be out of the bag ].

HR can also target the matrix subject position. This is found in Brazilian Portuguese (Ferreira 2009; Nunes 2008, a.o.), exemplified below, Lubukusu (Carstens \& Diercks, 2013), and Zulu (Halpert, 2016).
a. Parece [ que o João comprou um carro ]. seems [ COMP the João bought a car ] 'It seems that João bought a car.'
b. O João parece [ que $t$ comprou um carro ]. the João seems [ COMP $t$ bought a car ]

\footnotetext{
*For valuable discussion, I thank Danny Fox, Martin Hackl, Sabine Iatridou, David Pesetsky, Norvin Richards, various audiences at MIT, ECO5 (UConn, 2017), and the 2018 LSA meeting. All errors are my own. Author: Suzana Fong, Massachusetts Institute of Technology (sznfong@mit.edu).
} 
ECM/object shift constructions are illustrated below, again with English sentences.

a. Mary believes Anna with all her heart [ $t$ to have finished her paper already ].

b. Carol believes the cat $[t$ to have been out of the bag for a while now ].

The HR counterpart can be found in Mongolian, ${ }^{2}$ illustrated below, Korean (Yoon, 2007), Japanese (Tanaka 2002; Takeuchi 2010, a.o.), Nez Perce (Deal, 2017), Janitzio P'urhepecha (Zyman, 2017), Sakha (Baker \& Vinokurova, 2010), and Zulu (Halpert \& Zeller, 2014). In (4a), the embedded subject is assigned NOM case (morphologically null), as expected. In (4b), it is marked with ACC case. The ACC DP precedes the matrix adverb changaar 'loudly'.

a. Bat chang-aar [Dorj sain seheetin gej ] hel-sen.

Bat loud-INSTR [ Dorj.NOM good noble COMP ] say-PST

'Bat said loudly that Dorj is good and noble.'

b. Bat Dorj-iig chang-aar [ $t$ sain seheetin gej ] hel-sen.

Bat Dorj-ACC loud-INSTR [ $t$ good noble COMP ] say-PST

'Bat said loudly that Dorj is good and noble.'

As mentioned, a remarkable difference between $\mathrm{HR}$ and standard raising is that $\mathrm{HR}$ departs from a finite clause, while standard raising, from a nonfinite clause. The usual motivation attributed to standard raising is that nonfinite clauses are defective and therefore unable to assign case to the subject. As such, it has to rely on a matrix assigner to be licensed. But, in HR constructions, the embedded clause is finite, which is able to license a subject, as we can see in (2a) and (4a). In these sentences, the embedded subject sits where it is expected to be because it can be licensed there. Under this view, HR is unmotivated, so it should not be possible. This is the correct result for a language like English, which does not allow for HR to subject or to object:

a. *Alex seems [ that $t$ bought a car ].

b. *Alex believes Max with all their heart [ that $t$ has already finished the paper ].

However, as inferred from the data above, a general prohibition against HR is too strong.

HR challenges common assumptions made about the locality of syntactic operations. This restriction can be stated in terms of the Phase Impenetrability Condition (PIC):

Phase Impenetrability Condition (Chomsky, 2001, p. 14)

The domain of $\mathrm{H}$ [head of a strong phase] is not accessible to operations at ZP [the smallest strong phase]; only $\mathrm{H}$ and its edge are accessible to such operations.

Under common assumptions, a finite CP like the embedded clause in a HR construction is a phase. The PIC (6) says that the complement domain of that CP should be inaccessible to probes above it. As a consequence, a probe in the matrix clause ( $\mathrm{T}$ or $v$ ) should be unable to raise the subject of the embedded clause. This would preclude the possibility of HR. ${ }^{3}$

\footnotetext{
${ }^{2}$ The Mongolian data was elicited during the class Topics in the Grammar of a less Familiar Language (MIT, Spring/2017) and during Summer/2017 (MIT). Many thanks to M. Buyandelger and specially to U. Byambadalai for their patience and helpfulness! Without them, this work would not have been possible.

${ }^{3} \mathrm{HR}$ also introduces a challenge to the Activity Condition (Chomsky, 2001, p. 6), in that the position the em-
} 
But the PIC (6) also has enough leeway to allow for a potential goal to be visible to a probe outside the phase where it sits, since the edge of the phase is accessible to an external probe. The proposal to be put forth here capitalizes on this component of the PIC. Concretely, I will propose that there are A-features in the head of the embedded finite $\mathrm{CP}$ that trigger the movement of the embedded subject to the edge of that CP. From Spec-CP, it should be visible to a matrix probe $(\mathrm{T} / v)$. The PIC problem that HR introduces will thus be side-stepped by exploring a possibility that the definition of the PIC itself provides. Arguments in favor of this analysis will be provided by binding effects and long distance scrambling in Mongolian. Furthermore, a consequence of the analysis is that, if HR is triggered by an A-probe in COMP and if there can also be composite $\mathrm{A} / \overline{\mathrm{A}}$-probes (van Urk, 2015), we might expect for there to be a variety of HR that is triggered by this type of probe. Data from Kipsigis seem to corroborate this expectation.

2. HR involves raising. In this section, I will discuss basic properties of HR, trying to show that it involves raising from the embedded clause into the embedding clause.

A classic raising diagnostic is idiom preservation. In (7b), an example of HR to subject in $\mathrm{BP}$, the subject of the $S V$ idiom surfaces in the matrix clause and yet the idiomatic reading is preserved. This suggests that the subject of the embedded idiom has moved into the matrix clause, seeing that it could not have been base-generated there.
a. Parece [que a vaca foi pro brejo ]. seems [ COMP the cow went to-the swamp ] 'It seems that things went bad.'
b. A vaca parece [que foi pro brejo ]. the cow seems [ COMP went to-the swamp ] 'It seems that things went bad.'

Idiom preservation can also be seen in HR to object, illustrated by the Zulu data in ( $8 \mathrm{~b})$.
a. Ngi-lindel-a [ (ukuthi) i-qhina li-phum-e e-m-bize-ni ]. 1sG-expect-FV [ (that) AUG-5.steinbok 5.SM-exit-SUBJ LOC-9-pot-LOC ] 'I expect the secret to come out.'
b. Ngi-lindel-a i-qhina [ (ukuthi) li-phum-e e-m-bize-ni ]. 1SG-expect-FV AUG-5.steinbok [ (that) 5.SM-exit-SUBJ LOC-9-pot-LOC ] 'I expect the secret to come out.'

(Halpert \& Zeller, 2014, (15))

The preservation of idioms indicates that the raised or ECM-ed DP is not an argument of the matrix clause. Another diagnostic to the same effect is that the embedded position cannot be filled by an overt pronoun. This is illustrated below with BP (9) 4 and Mongolian (10).
As crianças parecem [ que (*elas) comeram doce ]. the children seem.PL [ COMP (*they) ate candy ]
'The children seem to have eaten candy.'

bedded subject moves from and the target of HR are both marked with case. See Fong (2017) for an overview of the problem and a multiple case checking-based solution.

${ }^{4}$ Uncited data from BP is my own. 
Dorj Nara-g chang-aar [ (*ter) sain gej ] hel-sen.

Dorj Nara-ACC loud-INSTR [ (*3SG) good COMP ] say.PST

'Dorj said loudly that Nara will come tomorrow.'

If the DPs as crianças 'the children' or Nara and the embedded subject position in (9) and (10) respectively were just independent of each other (though coreferent), we could have expect that the embedded position could be filled by an overt pronoun. This is a reasonable expectation if we consider that all the languages mentioned display some type of pro-dropping. As such, the matrix DP in the constructions of interest could actually be base-generated there and resumed by a null pronoun in the embedded clause. However, inserting a pronoun in the embedded subject position renders the sentence ungrammatical.

Further diagnostics point to the conclusion that relationship between a matrix DP and an embedded gap in HR sentences is created by movement. A straightforward way to diagnose movement is island sensitivity. If the constructions described as HR involve movement, we predict that the gap the hyper-raised DP is associated with should not be inside an island. The prediction is correct, as can be seen from the BP data below.

(11) a. Parece que começou a chover [adjunct depois que alguns alunos chegaram ]. seem.SG COMP started to rain.INF [ after COMP some students arrived ] 'It seemed to start to rain after some students arrived.'

b. *Alguns alunos parecem que começou a chover [adjunct depois que chegaram ]. some students seem.PL COMP started to rain.INF [ after COMP arrived ] Int.: 'It seemed to start to rain after some students arrived.'

Island sensitivity can be witnessed in Nez Perce too. The embedded subject in (12a) bears the expected embedded subject case, namely, NOM, the case of intransitive verbs in a tripartite system like Nez Perce (Deal, 2017). Nevertheless, the matrix verb displays object agreement that crossreferences the embedded subject. Deal analyzes (12a) as involving HR to object, explaining the matrix object agreement, but covertly, explaining why the hyper-raised DP still surfaces in the embedded clause. (12b) corroborates the hypothesis that (12a) involves movement: this sentence is ungrammatical because the hyper-raised DP is inside an island.

a. 'Aayat-onm hi-nees-nek-se

[CP mamay'ac hi-pa-paay-no' ]. wOMan-ERG 3SUBJ-O.PL-think-IMPERF [ children.NOM 3SUBJ-S.PL-arrive-FUT ] 'The woman thinks the children will arrive tomorrow.'

b. *'Aayato-nm hi-nees-nek-se [ [ [ [adjunct ke kaa mamay'ac woman-ERG 3SUBJ-O.PL-think-IMPERF [ [ when children.NOM hi-pa-paay-no' ], hi-lloy-no' qiiwn ]. 3sUBJ-S.PL-arrive-FUT ], 3sUBJ-be.happy-FUT old.man.NOM ] Int.: 'the woman thinks that when the kids arrive, the old man will be happy.'

(Deal, 2017, (13/12))

Finally, reconstruction facts provide quite a compelling argument for movement in HR. The HR example (13b) allows for an inverse scope reading. Importantly, the same reading is available for the non-HR baseline (13a), where the higher quantifier dois soldados 'two soldiers' is inside the embedded clause. The availability of an inverse scope reading in (13b) can be ex- 
plained if dois soldados is base-generated inside the matrix clause, so that todas as batalhas 'every battle' can locally take scope over it. Both these sentences can be roughly paraphrased as 'it seems that, for every battle, two (different) soldiers die in it'. ${ }^{\prime}$

a. Parece [ que dois soldados morrem em todas as batalhas ]. seems [ COMP two soldiers die in every the battles ] 'It seems that two soldiers die in every battle.'

b. Dois soldados parecem [ que morrem em todas as batalhas ]. two soldiers seem [ COMP die in every the battles ] 'Two soldiers seem to die in every battle.'

Reconstruction effects in NPI licensing can be seen in HR to object in Sakha. Here, the NPI is kim-ye daqany 'anyone'. If it is base-generated in the matrix clause (in (14a), as the addressee argument of et 'tell'), while negation is in the embedded verb, the result is ungrammatical. In (14b), the NPI is in ACC form (kim-i daqany) and it is interpreted as the embedded subject. Negation is again attached to the embedded verb, but the result is grammatical. A HR analysis can account for why $(14 b)$ is grammatical, while (14a) is not.
a. *Min kim-ne daqany [ pro kel-bet
dien ] et-ti-m
I who-DAT PRT [ pro come-NEG.AOR.3sS that ] tell-PAST-1sS
'I told no one to come.' (lit. 'I told anyone that he should not come.')
b. Min kim-i daqany [ kyaj-ba-ta dien ] eren-e-bin.
I who-ACC PRT [ win-NEG-PAST.3sS that ] hope-AOR-1sS
'I hope that nobody won (the lottery).'

(Baker \& Vinokurova, 2010, (42/43))

In this section, we established that HR does indeed involve raising. We now turn to a comparison of HR with other constructions that we could plausibly conflate HR with, namely, copyraising and prolepsis. Since these constructions do not involve movement, we will see that reducing HR to these constructions is misguided.

As mentioned, all the languages above that have HR also allow for pro-dropping. A reasonable hypothesis is that what is called HR here actually involves base-generation of a DP in the matrix clause that is linked with a null pronoun in the embedded clause. Two constructions that display these properties are copy-raising and prolepsis.

Copy-raising (in English) (Landau, 2011, p. 783)

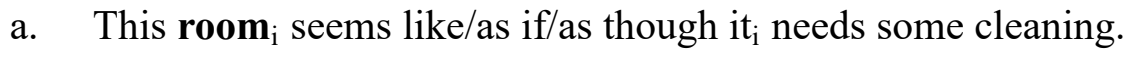

b. Suzan $_{\mathrm{i}}$ sounded like/as if/as though Frank really offended her ${ }_{\mathrm{i}}$.

Prolepsis (in English) (Davies, 2005, (6/34))

a. I believe about Kate that she won the Daughter-of-the-Year award.

b. Sheryl thought about/of Tim that the police would never catch him.

HR to subject could be compared to copy-raising (15), where a DP occupies the matrix subject position and is linked with a pronoun in an embedded finite clause. HR to object could be analo-

\footnotetext{
${ }^{5}$ As demonstrated in Fong (2017), quantifiers base-generated in a finite embedded clause cannot scope over matrix quantifiers.
} 
gized to prolepsis (16), where a DP occupies a matrix object position and is also linked with a pronoun in the embedded finite clause. The difference between (15) and (16) and HR would be that in the latter, the embedded pronoun is not pronounced, since the HR languages mentioned allow for a dropped subject. Nevertheless, a first argument against reducing HR to copy-raising or to prolepsis is suggested by the fact that the embedded position in HR constructions cannot be overtly filled with a pronoun, as we saw in the BP and Mongolian data in (9) and (10).

Further evidence that HR to subject and copy-raising are not the same is provided by reconstruction. Recall from (13b) that a hyper-raised quantifier in HR to subject in BP can be reconstructed back into the embedded clause. In contrast, in the copy-raising example (17), the matrix DP two soldiers has to take wide scope. ${ }^{6}(17)$ is roughly paraphraseable as '(the same) two soldiers seem like they die in every battle'.

Two soldiers seem like they die in every battle.

Xevery $>$ two

The lack of an inverse scope reading in (17) can be explained if the DP that surfaces in the matrix clause in a copy-raising construction is actually base-generated there (cf. Landau 2011).

We now turn to the possibility of analyzing HR to object as an instance of prolepsis (16). Idiom preservation and island sensitivity facts allow us to tease them apart. The Zulu HR to object data in (8b) was a sample of the preservation of idioms in HR to object. In prolepsis constructions, however, idioms are not preserved:

a. Yuri said about the cat that it/(s)he is out of the bag.

(literal only)

b. Yuri said about the bucket that Anna kicked it.

(iteral only)

If $\mathrm{HR}$ to object and prolepsis were the same construction, an idiom preservation difference would not be expected. In contrast, if prolepsis is derived by the base-generation of the matrix DP in the matrix clause itself (cf. Davies 2005), while HR to object is derived via movement, the difference can be accounted for.

Likewise, a contrast in island sensitivity argues against reducing HR to object and prolepsis to the same analysis. We saw in (12b), an example of HR to object in Nez Perce, that this is not allowed from adjuncts. In contrast, a proleptic pronoun can be located inside an adjunct:

Ravi said about Max $\mathbf{x}_{1}$ [that it started raining [adjunct only after they ${ }_{1}$ were already indoors]].

This island-sensitivity contrast could not be explained if HR to object and prolepsis were the same. Again, a straightforward explanation is that prolepsis involves base-generation of a DP in the matrix clause, so that no island violation is incurred. The opposite holds of HR, hence the ungrammaticality of (12b).

In this section, we examined raising diagnostics, concluding that HR involves movement. But the movement established above departs from a finite clause, in violation of the PIC (6). In the next section, we turn to an analysis that tries to circumvent this problem.

3. Analysis: movement to the edge. Since HR departs from a finite clause, it seems to be a violation of the PIC (6). But recall that there is an escape hatch position hardwired into the

\footnotetext{
${ }^{6}$ Thank you to N. Richards (p.c.) for discussion and data.
} 
PIC: the edge of a phase is visible to a probe in the higher phase. Along with other proposals (Tanaka 2002, Zyman 2017, a.o.), I will explore that possibility to provide a solution to PIC problem. Specifically, I propose that the complementizer in the complement of HR sentences has A-features (i.e. features that create A-positions; they will be motivated in $\S 4$.), that trigger the movement of the embedded subject to Spec-CP. Being at the edge of the phase, the embedded subject is now visible to a matrix probe, $\mathrm{T}$ or $v$, giving rise to HR to subject and to object, respectively. ${ }^{7}$

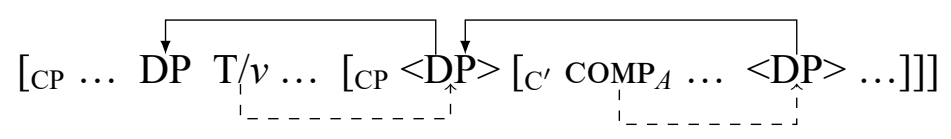

Figure 1: HR triggered by A-features in COMP

This proposal has a crucial component: it implies that HR is not the direct movement of the embedded subject all the way into the matrix clause. Rather, the embedded subject stops over at the edge of the embedded clause Spec-CP first. In what follows, I try to provide two pieces of evidence in support of this analysis, one from medial-raising and another from scrambling.

3.1. Medial-Raising. The first piece of evidence that an intermediate movement to Spec-CP is relevant in the derivation of $\mathrm{HR}$ will come from constructions where the subject of an embedded finite clause stays inside the embedded clause and yet is able to interact with the matrix clause for both binding and case marking purposes. For convenience, I dub this variety of HR medialraising.

The discussion that ACC finite subjects in Mongolian can stay inside the embedded clause has two parts. First, I show that the ACC can follow unambiguously embedded adverbs and also be part of a scrambled clause. Data of this type, however, leaves unspecified the position in the embedded clause where the ACC subject is. That is when we turn to binding data, which will suggest that embedded clause-internal ACC subjects have to be in a higher position than Spec-TP.

In (20a), the verb helsen 'said' takes a finite complement and the subject (Dulmaa) bears NOM case. In (20b), the embedded subject now bears ACC. Despite this difference, the embedded subject is preceded by the adverb margaash, which unambiguously modifies the embedded clause (the matrix verb is in the past). This suggests that a subject can be marked with ACC case while remaining in the embedded clause.
a. Bat [ margaash Dulmaa nom unsh-n gej ] hel-sen. Bat [ tomorrow Dulma.NOM book read-N.PST COMP ] say-PST 'Bat said that Dulma will read a book tomorrow.'
b. Bat [ margaash Dulmaa-g nom unsh-n gej ] hel-sen. Bat [ tomorrow Dulma-ACC book read-N.PST COMP ] say-PST 'Bat said that Dulma will read a book tomorrow.

\footnotetext{
${ }^{7}$ Since the features that create Spec-CP are A-features, HR through that position in fig. 1 is not an instance of improper movement. To recall, I assuming van Urk (2015)'s featural definition of syntactic positions, to be briefly summarized below.
} 
(20) is an instance of what I dubbed 'medial-raising': the embedded subject seems to stay inside the embedded clause, as diagnosed by adverb placement, and yet it is marked with ACC case.

Another argument for medial-raising comes from the fact that the whole embedded clause can be scrambled, while still containing an ACC subject. (21a) shows that ACC case is not a possibility for a possessum in an unembedded clause. (21b) shows that this is nevertheless a possibility in a finite embedded clause. (21b) is to be contrasted with (21c), where the whole embedded clause is moved to the left; the possessum still bears ACC case.
a. Sharlovan(*-g) Bat-id baigaa.
carrot $(*$-ACC) Bat-DAT COP
'Bat has a carrot.'
b. Dulmaa chang-aar sharlovan-g Bat-id [baigaa gej ] hel-sen.
Dulma loud-INSTR carrot-ACC Bat-DAT [ COP COMP ] say-PST
'Dulma said loudly that Bat has a carrot.'
c. [Sharlovan-g Bat-id baigaa gej ] Dulmaa chang-aar Dorj-id $t$ hel-sen. [ carrot-ACC Bat-DAT COP COMP ] Dulma loud-INSTR Dorj-DAT $t$ say-PST 'That Bat has a carrot, Dulma said loudly to Dorj.'

(21c) is an instance of medial-raising: the embedded subject is pied-piped along by the scrambled clause that contains it and, relevantly, it still bears ACC case.

These data suggest that, in Mongolian, a subject can be marked with ACC case while staying inside the embedded clause (i.e. medial-raising is a possibility). Nothing was said, however, about the exact position occupied by the ACC subject. It could well be the case that it stays in the canonical subject position, Spec-TP. In this case, what I am calling 'medial-raising' here would just be ECM across a finite CP. However, binding data suggest that the position that a medialraised DP occupies in the embedded clause is not Spec-TP, but a higher position. ${ }^{8}$

3.2. Medial-Raising AND Binding. The reflexive possessive -ee (whose form is subject to vowel harmony) has to be locally bound. In (22a), -ee is attached to the only nominal in the sentence. The sentence is ungrammatical as a consequence of the lack of an antecedent. If -ee is taken away, as in (22b), the result is grammatical. (22c) shows that the presence of an antecedent is not sufficient. In (22c), -ee is the subject of the most deeply embedded nominalized clause. The antecedent has to be the closest subject (Nara) and cannot be the highest subject (Bat).
a. *Margaash egch-ee ir-ne. tomorrow sister.NOM-REFL.POSS come.N.PST Int.: 'My sister is coming tomorrow.'
b. Margaash egch/egch miin ir-ne. tomorrow sister.NOM/sister.NOM POSS come.N.PST 'My sister is coming tomorrow.'
c. Bat $_{1}\left[\mathrm{Nara}_{2}\left[\right.\right.$ muur har-sn-iig-aa $\left.*_{1 / 2}\right]$ hel-sen gej ] med-n.
Bat [ Nara [ cat see-PST-ACC-POSs ] say-PST COMP ] know-N.PST 'Bat knows that Nara said that she saw a cat.'

\footnotetext{
${ }^{8}$ Very similar data in Buryat was first discussed by Bondarenko (2017), who also concludes that HR requires a stopover position in Spec-CP.
} 
(Lit.: 'Bat 1 knows [that $\operatorname{Nara}_{2}$ said [- $a a_{* 1 / 2}$ saw a cat]])'

Consider now the behavior of reflexive possessive -ee in the subject of embedded finite clauses. If it is appended to a NOM subject (23a), the sentence is ungrammatical. We can explain (23a)'s ill-formedness by saying that the reflexive possessive cannot be bound by the matrix subject because the latter is outside the binding domain of the reflexive. This in turn implies that a finite embedded clause can in principle be the binding domain of the embedded subject.
a. Bat chang-aar [ egch-ee gaikhal-tai gej ] hel-sen.
Bat loud-INSTR [ sister-REFL.POSS wonder-with COMP ] say-PST
Int.: 'Bat said loudly that his (own) sister is wonderful.'
b. *Bat [ margaash egch-ee ir-ne gej ] hel-sen.
Bat [ tomorrow sister-REFL.POSS come-N.PST COMP ] say-PST
Int.: 'Bat said that his (own) sister is coming tomorrow.'

Conversely, if the subject is ACC, the result is grammatical. Significantly, in (24b), the ACC subject containing -ee follows the embedded adverb margaash 'tomorrow', suggesting that the ACC subject is still inside the embedded clause. In (24c), the embedded clause as a whole was scrambled, including the -ee-containing ACC subject. (24b) and (24c) are examples of medial-raising and, nevertheless, the reflexive possessive can be bound by the matrix subject.
a. Bat egch-iig-ee chang-aar [gaikhal-tai gej ] hel-sen.
Bat.NOM sister-ACC-REFL.POSs loud-INSTR [ wonder-with COMP ] say-PST
'Bat ${ }_{1}$ said loudly that his ${ }_{1 / 2}$ (own) sister is wonderful.'
b. Bat [margaash egch-iig-ee ir-ne gej ] hel-sen.
Bat.NOM [ tomorrow sister-ACC-REFL.POSS come-N.PST COMP ] say-PST
'Bat said that his (own) sister is coming tomorrow.'
[ sister-ACC-REFL.POSS come-N.PST COMP ] Bat.NOM $t$ say-PST
'That his (own) sister is coming, Bat said.'
c. [ Egch-iig-ee ir-ne gej ] Bat $t$ hel-sen.

If the ACC subject in these sentences were occupying the same position as a NOM subject, (24b) and (24c) should be as ungrammatical as the sentences in (23), contrary to fact. How then can we account for the fact that the ACC subjects in (24b) and (24c) seem to stay inside the embedded clause, while also being bound by the matrix subject? In other words, what position could a medial-raised subject be occupying so that it can be bound by the matrix clause and receive ACC case from the matrix, but staying in the embedded clause all the while? Spec-CP in fig.1 provides this type of dual position: it is inside the embedded clause, but it extends the binding domain of the medial-raised subject, which now includes the matrix subject. ${ }^{9}$ By virtue of being at the edge of a phase, the medial-raised DP can also receive ACC from the matrix without exiting the embedded clause.

This higher position distinguishes medial-raising from garden-variety ECM, where it suffices for a subject to stay in its canonical position (e.g. Spec-TP) to receive ACC.

\footnotetext{
${ }^{9}$ The relevance of Spec-CP for binding in medial-raising is reminiscent of sentences such as the following: Which picture of himself did John $_{1}$ say [CP $\boldsymbol{t}$ that Bill liked t best ]?
} 
3.3. Medial-RAising AND LONG DistanCE SCRAmbling. We concluded above that Spec-CP was the position where medial-raised DPs receive ACC case. What then happens to ACC subjects that are effectively pronounced in the matrix clause, as in e.g. (4b)? I follow Hiraiwa (2005)'s and Bondarenko (2017)'s analyses of HR to object in Japanese and Buryat, respectively. In particular, Bondarenko argues that medial-raising in Buryat can be optionally followed by scrambling. I will call 'long distance scrambling' the scrambling of nominals out of an embedded finite clause.

(25) illustrates the positions that a hyper-raised DP can occupy in Mongolian. In (25a), the ACC is inside the matrix clause, as it precedes an unambiguously matrix adverb. It is also possible for an ACC subject to be realized in the left-most position of the matrix clause, $(25 \mathrm{~b})$.
a. Bat $\{$ nokhoi-g $\}$ chang-aar $[\{$ nokhoi $\}$ gaikhal-tai gej $]$ hel-sen. Bat $\{$ dog-ACC $\}$ loud-INSTR [ $\{$ dog.NOM $\}$ wonder-with COMP ] say-PST 'Bat said that dogs are wonderful.'
b. $\{$ Dulmaa-g $\}$ Bat [ $\{$ Dulmaa $\}$ nom unsh-n gej $]$ hel-sen. $\{$ Dulma-ACC $\}$ Bat [ $\{$ Dulma.NOM $\}$ book read-N.PST COMP ] say-PST 'Bat said that Dulmaa will read a book.'

Consider now the long distance scrambling of non-ACC DPs. In fact, if the same matrix positions are occupied by an embedded NOM DP, as in (26), or a DAT DP, as in (27), the result is ungrammatical.
a. Bat $\left\{{ }^{*}\right.$ Dorj $\} \quad$ chang-aar $[\{\checkmark$ Dorj $\} \quad$ sain seheetin gej $]$ hel-sen. Bat $\{*$ Dorj.NOM $\}$ loud-INSTR $[\{\checkmark$ Dorj.NOM $\}$ good noble COMP $]$ say-PST 'Bat said loudly that Dorj is good and noble.'
b. $\quad\{*$ Dorj $\}$ Bat $[\{\checkmark$ Dorj $\}$ Dulmaa-d nom-oo ög-sön gej $]$ med-n. $\{*$ Dorj $\}$ Bat $[\{\checkmark$ Dorj $\}$ Dulma-DAT book-REFL.POSS give-PST COMP $]$ know-N.PST Int: 'Bat knows that Dorj gave his book to Dulma.'

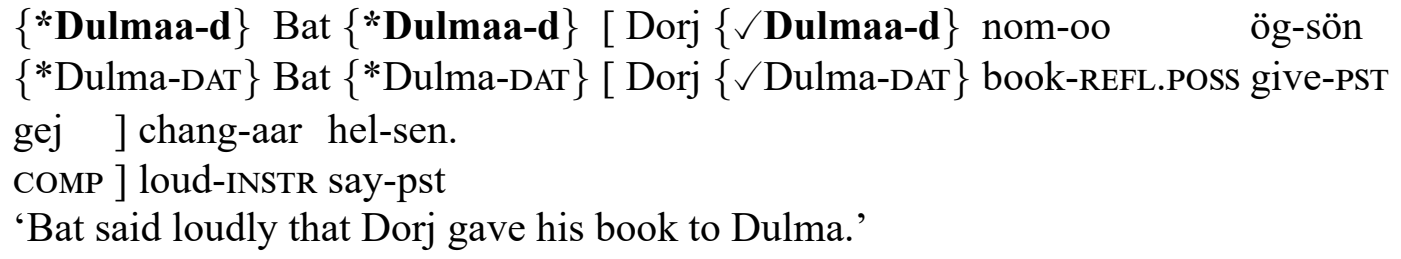

(26) and (27) seem to establish that long distance scrambling is not a possibility in Mongolian. We now find ourselves in a bind. Given the possibility of medial-raising in Mongolian, if an ACC finite subject is placed in the matrix clause, this would have to be a consequence of long distance scrambling. But, if we try to long distance-scramble a non-ACC DP, the result is ungrammatical.

I propose that long distance scrambling is not possible in Mongolian, at least not of NOM or DAT DPs. This proposal tries to account for the ill-formedness of (26) and (27) by brute force. But, when combined with the edge-based analysis of HR, it also provides a way to model the possibility of scrambling ACC subjects. Scrambling out of a finite embedded clause is only possible if the scrambling DP first moves to Spec-CP, as a consequence of the A-features in $\mathrm{C}$. From that position, it will receive ACC from the matrix clause. Being at the edge of a phase, the ACC subject can scramble locally into the matrix clause. Assuming that case assignment is local and obligatory, the DP moved to Spec-CP will receive ACC, explaining why these DPs cannot surface 
with NOM (26). Assuming locality and minimality restrictions, the embedded subject will be targeted by the A-features in COMP, ruling out the possibility of lower DAT DPs to be reached (27). ${ }^{10}$

The proposal that HR involves a stopover position in Spec-CP thus also provides an explanation as to why scrambling of ACC subjects is possible, even though long distance scrambling seems to not be a possibility in Mongolian.

4. HR as A-movement: towards a featural definition of syntactic positions. I proposed that a key component in the derivation of HR is movement to Spec-CP that triggered by A-features (i.e., features that create A-positions; van Urk 2015). In this section, I try to support the claim that HR is a type of A-movement, even though it passes through Spec-CP.

The first piece of evidence that HR is a type of A-movement is furnished by the creation of new antecedents for binding in Japanese.

$$
\begin{aligned}
& \left\{\text { karera-o }_{\mathrm{i}}\right\} \text { otagai-no }_{\mathrm{i}} \quad \text { sensei-ga } \quad\left\{\text { ??karera-o }_{\mathrm{i}}\right\}\left[t_{\mathrm{i}} \text { baka-da-to }\right] \text { omot-teiru. } \\
& \text { \{they-ACC }\} \text { each other-GEN teacher-NOM \{they-ACC } \quad \text { [ } t \text { fool-COP-COMP }] \text { think-PROG } \\
& \text { 'Each other }{ }_{i} \text { 's teachers think of them }{ }_{i} \text { as fools.' }
\end{aligned}
$$

(adapted from Tanaka 2002, p. 640)

As Tanaka (2002) remarks, this is a signature property of A-movement and not of $\bar{A}$-movement. If $\mathrm{HR}$ indeed passes through Spec-CP, this has to an A-position, otherwise the sentences in (28) would be incorrectly ruled out as instances of improper movement.

Similarly, as observed by Ferreira (2009) and Nunes (2008), HR to subject in BP can trigger verbal agreement in both the matrix and the embedded verb (29). As Ferreira and Nunes remark, verbal agreement is triggered exclusively by A-movement in BP.

As crianças parece-m [ que $t$ comera-m doce ]. the children seem-3PL [ COMP $t$ ate-3PL candy ] 'The children seem to have eaten candy.'

Likewise, HR in BP can bind variables without inducing weak cross-over effects:

Nenhum aluno 1 parece pro orientador dele ${ }_{1}[t$ que entendeu a lição $]$. no student seem for.the advisor of.he [ $t$ COMP understood the lesson ] 'No students seems to his advisor to have understood the class.'

The creation of new antecedents for binding, passivization, and $\phi$-agreement are signature properties of A-movement. Based on this data, we could conclude that $\mathrm{HR}$ is an instantiation of A-movement. If it is indeed the case that HR presupposes an intermediate position, Spec-CP, then this position would also have to be of the A-type. If correct, this conclusion is incompatible with the common view of syntactic positions according to which they are inherently A or $\bar{A}$, Spec-CP being an example of the latter type. An alternative view is that in van Urk (2015), where syntactic positions are defined featurally: if a syntactic position is created by an operation based on $\alpha$-features, it is an $\alpha$-position, $\alpha$ ranging over ' $\mathrm{A}$ ' and ' $\overline{\mathrm{A}}$ '. If the present analysis

\footnotetext{
${ }^{10}$ It is worth clarifying that Spec-CP in the present analysis is not a general "escape hatch" position that e.g. a lower DAT argument could scramble through. Spec-CP is created by A-features in COMP. A by-product of occupying this position is bringing the embedded subject close enough to the matrix clause, so that it can scramble into it, overriding a ban on long distance scrambling.
} 
is on the right track, it provides further support for a featural definition of syntactic positions, as opposed to identifying them as being inherently $\mathrm{A}$ or $\overline{\mathrm{A}}$.

4.1. HR OF LOWER ARGUMENTS ACROSS THE SUBJECT. According to van Urk (2015), the upshot of a featural definition of syntactic positions is that, if there is a syntactic operation that is driven by both $\mathrm{A}$ - and $\overline{\mathrm{A}}$-features (i.e. a composite probe), there should be syntactic positions that display hybrid properties too. Van Urk shows that this can be seen in Dinka.

Dinka is a V2 language where the phrase that moves to the initial position triggers $\phi$-agreement. This can be seen in (31c), where the V2 verb agrees with the object that moved to its left. The object moves across the subject. $\phi$-agreement is a typical property of A-positions, while the skipping over of higher goals is a typical property of $\overline{\mathrm{A}}$-movement.
a. Yị̂in Ø-cí môc tị̂ị.
you 2-PRF-OV man.GEN see.NF
'You, the man has seen.'
b. Mìir à-càa tị̂in. giraffe 3SG-PRF.1SG see.NF 'A giraffe, I have seen.'
c. Miècr áa-càa ké tị̂ị. giraffes 3PL-PRF.1SG 3PL see.NF 'Giraffes, I have seen.'

(van Urk, 2015, p. 103)

In order to reconcile these two properties, van Urk proposes that $\mathrm{C}$ in Dinka has both an A- and an $\overline{\mathrm{A}}$-probe, the fulfilling of which creates a hybrid position (Spec-CP).

In (32), mòc ẹ́bẹ́n 'every man' moves from the embedded clause into the left periphery of the matrix clause. Cross clausal movement is usually taken to be a property of $\overline{\mathrm{A}}$-movement. However, the moved quantifier phrase can bind a pronoun that it moves across. This is an obviation of a weak crossover effect, a property of A-movement.

$$
\begin{aligned}
& \text { Mòc ẹ́bện } \text { à-yíi tiéen-dè }_{\mathrm{i}} \text { luêeel [CP è̀ _thet ]. } \\
& \text { man every 3s-HAB-OV woman-SG.3sG say.NF [ C _ cook.Sv ] } \\
& \text { 'Every } \operatorname{man}_{1} \text {, his } 1 \text { wife says is cooking.' }
\end{aligned}
$$

(van Urk, 2015, p. 110)

Again, these properties can be accounted for in a unified way by the proposal that the movement of mòc ẹ́bẹ́n is triggered by a composite $\mathrm{A} / \overline{\mathrm{A}}$-probe. This brief summary provides the empirical motivation behind composite probes. See more details in van Urk (2015).

We now have two ingredients, the HR analysis put forth here based on A-features in COMP and the composite probes from van Urk (2015). If we combine these ingredients, the expected consequence is that there could be a type of HR that is triggered by a composite $\mathrm{A} / \mathrm{A}$-probe. This is possibly true of HR to object in Kipsigis.

Jake \& Odden (1979) argue that embedded subjects and non-subject lower arguments can hyper-raise in Kipsigis. (33) is a basic paradigm where a DP realized in the matrix clause is interpreted semantically as the subject of the embedded clause. In (33b), the embedded subject bears different tone marking than in (33a). It is also placed inside the matrix clause, where it precedes the matrix subject (Mù:sá). 

a. mócè Mùssá [ kólápát Kíplànàt ].
wants Musa [ run Kiplangat ]
'Musa wants Kiplangat to run.'
b. mócè Kìplàyàt Mùsá [ kólápát ].
wants Kiplangat Musa [ run ]
'Musa wants Kiplangat to run.'

(Jake \& Odden, 1979, (7))

(34) is a similar paradigm, but now the DP that is realized in the matrix clause is interpreted not as the embedded subject, as in (33), but as the embedded object.
a. mócè Mù:sá [ kó-tíl Kíplàyàt pè:ndó ]. wants Musa [ 3s.suB-cut Kiplangat meat ] 'Musa wants that Kiplangat cut the meat.'
b. mócè pè:ndó Mù:sá [ kó-tíl Kíplànàt ]. wants meat Musa [3s.sub-cut Kiplangat ] 'Musa wants that Kiplangat cut the meat.'

(Jake \& Odden, 1979, (11))

If (34) is an instance of HR of an embedded object (to the matrix object position), then Kipsigis introduces an additional minimality challenge, in that a lower DP is moving across the embedded subject, which is itself a candidate to move, as we saw in (33).

That these constructions in fact involve HR is suggested by two arguments. First, it obeys locality. In a sentence with three levels of embedding, if the subject (35a) or object (35b) of the most deeply embedded clause hyper-raises into the highest clause skipping over the intermediate clause, the result is ungrammatical. In (35a) and (35b), HR is supposed to be expressed by the prefixes that cross-reference the most embedded subject and object, respectively.
a. *ó-móc-í:n [ kò-yáy Mù:sá [ ì-till-ín pè:ndó ] ]. 1s-want-2s [3s-make Musa [2s-cut meat ]]
Int.: 'I want that Musa make you cut the meat.'
b. *ó-móc-í:n [ kò-yáy Mù:sá [ kò-tìl-ín Kíplàyàt ] ]. 1s-want-2s [ 3s-make Musa [3s-cut-2s Kiplangat ] ] Int.: 'I want that Musa make Kiplangat cut you.'

(Jake \& Odden, 1979, (18))

(35a) and (35b) contrast with prolepsis, where a proleptic constituent can be resumed by a proleptic pronoun two clauses down:

(36) I know of Alex 1 [that Max said [that they ${ }_{1}$ are the best candidate for the job]].

Second, if a DP is inactive for further syntactic operations, it is also inactive for HR. In (37a), a passivized object is topicalized. in (37b) the agent of the passive undergoes topicalization, but the result is ungrammatical.
a. pè:ndó kó-kà-kí-tîl Mù:sá.
meat TOP-PAST-PASS-cut Musa
'The meat was cut by Musa.'
Musa TOP-PAST-PASS-cut meat
Int.: 'The meat was cut by Musa.'
b. *Mû:sá kó-kà-kí-tîl pè:ndó.

(Jake \& Odden, 1979, (49)) 
While it is not obvious why (37b) should be ungrammatical, what is relevant to the purposes here is that agents of passives cannot undergo HR either:

a. ó-mócé pè:ndó [ ké:-tíl Kíplànàt ].
1s-want meat [ PASS-cut Kiplangat ]
'I want the meat to be cut by Kiplangat.'
b. *'o-mócé Kìplànàt [ ké:-tíl pè:ndó ].
1s-want Kiplangat [ PASS-cut meat ]
Int.: 'I want the meat to be cut by Kiplangat.'
(Jake \& Odden, 1979, (50))

The ungrammaticality of (38b) must be contrasted with the well-formedness of the sentences in (34) above. In both, the matrix verb is mócé 'want' and in both sentences the same DP surfaces in the matrix clause (Kìplàyàt). If these constructions were just instances of prolepsis, $(38 \mathrm{~b})$ and (34) should all be equally well- or ill-formed, contrary to fact. There is some suggestion then that these Kipsigis sentences are instances of HR and not of prolepsis.

We may tentatively conclude that Kipsigis have HR and furthermore of a particular type: an embedded argument that is lower than the subject is what hyper-raises. As mentioned, this introduces an extra minimality problem. I propose that, in this type of construction, COMP has a composite $\mathrm{A} / \overline{\mathrm{A}}$-probe. An appropriate goal for this type of hybrid probe has to have matching features. If the embedded subject does not have them, it will be skipped over. Conversely, if the object bears $\mathrm{A} / \overline{\mathrm{A}}$-features, it will be an adequate goal, allowing it to be hyper-raised.

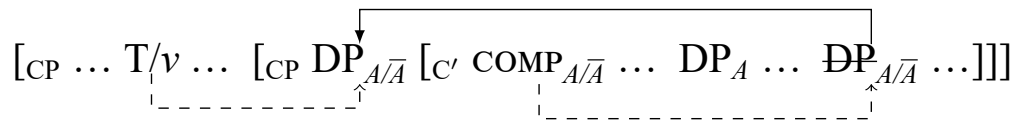

Figure 2: HR of object across subject triggered by composite $\mathrm{A} / \overline{\mathrm{A}}$-probe

Under this view, there is no minimality violation in the derivation of the Kipsigis sentences where a lower argument seems to be hyper-raising. The embedded object can raise across the embedded subject because it is the only appropriate goal for a composite probe.

5. Conclusion. I proposed in this paper that movement to the edge of the embedded clause was a necessary intermediate movement in the derivation of HR. This proposal received empirical support from Mongolian, where the medial-raised subject can in fact stay inside the embedded clause. The edge of the embedded provides this dual position, since it is still inside the embedded clause, while also being accessible to a matrix probe. Interaction with long distance scrambling in the same language also argued in favor of the analysis proposed. Taking into consideration the fact that HR can feed A-movement in Japanese and BP, I also proposed that Spec$\mathrm{CP}$ is an A-position. This runs counter to the common assumption that Spec-CP is necessarily an $\overline{\mathrm{A}}$-position. With the addition of composite probes, a free outcome of the analysis is that it is capable to account for the variety of HR that is found in Kipsigis, where a DP that is lower than the embedded subject seems to be able to hyper-raise. If correct, the proposal put forth here lends further support to a featural view of syntactic positions, as well as to composite, A/A-probes (cf. van Urk 2015). 


\section{References}

Baker, Mark \& Nadya Vinokurova. 2010. Two modalities of case assignment: Case in Sakha. Natural Language \& Linguistic Theory, 28(3), 593-642.

Bondarenko, Tatiana. 2017. ECM in Buryat and the optionality of movement. In: Zidani-Eroğlu, Leyla, Ciscel, Matthew \& Koulidobrova, Elena (eds), Proceedings of the 12th Workshop on Altaic Formal Linguistics (WAFL 12). MIT Working Papers in Linguistics, no. 83. Cambridge, MA: MITWPL.

Carstens, Vicki \& Michael Diercks. 2013. Parameterizing case and activity: Hyperraising in Bantu. In: Kan, Seda, Moore-Cantwell, Claire, \& Staubs, Robert (eds), Proceedings of NELS 40.

Chomsky, Noam. 2001. Derivation by phase. In: Kenstowicz, Michael (ed), Ken Hale: A life in language. Cambridge, MA: MIT Press.

Davies, William. 2005. Madurese prolepsis and its implications for a typology of raising. Language, 645-665.

Deal, Amy Rose. 2017. Covert hyperraising to object. In: Lamont, Andrew, \& Tetzloff, Katerina (eds), Proceedings NELS 47.

Ferreira, Marcelo. 2009. Null subjects and finite control in Brazilian Portuguese. In: Nunes, Jairo (ed), Minimalist essays on Brazilian Portuguese syntax. Amsterdam: John Benjamins.

Fong, Suzana. 2017. A featural and edge-based analysis of hyper-raising. MIT (ms.).

Halpert, Claire. 2016. Raising parameters. Pages 186-195 of: Kim, Kyeong-min, Umbal, Pocholo, Block, Trevor, Chan, Queenie, Cheng, Tanie, Finney, Kelli, Katz, Mara, NickelThompson, Sophie, \& Shorten, Lisa (eds), Proceedings of WCCFL 33. Cascadilla Proceedings Project.

Halpert, Claire \& Jochen Zeller. 2014. Right dislocation and raising-to-object in Zulu. The Linguistic Review, 32(3).

Hiraiwa, Ken. 2005. Dimensions of symmetry in syntax: Agreement and clausal architecture. Ph.D. thesis, Massachusetts Institute of Technology.

Jake, Janice, \& David Odden. 1979. Raising in Kipsigis. Studies in the Linguistic Sciences, 9(2), $131-155$.

Landau, Idan. 2011. Predication vs. aboutness in copy raising. Natural Language \& Linguistic Theory, 29(3), 779-813.

Nunes, Jairo. 2008. Inherent Case as a licensing condition for A-movement: The case of hyperraising constructions in Brazilian Portuguese. Journal of Portuguese Linguistics, 7(2), 83-108.

Takeuchi, Hajime. 2010. Exceptional case marking in Japanese and optional feature transmission. Nanzan Linguistics, 6, 101-128.

Tanaka, Hidekazu. 2002. Raising to object out of CP. Linguistic Inquiry, 33(4), 637-652.

van Urk, Coppe. 2015. A uniform syntax for phrasal movement: A Dinka Bor case study. Ph.D. thesis, MIT.

Yoon, James H. 2007. Raising of major arguments in Korean and Japanese. Natural Language \& Linguistic Theory, 25(3), 615-653.

Zyman, Erik. 2017. P'urhepecha hyperraising to object: An argument for purely altruistic movement. Proceedings of the Linguistic Society of America, 2, 53:1-15. https://doi.org/10.3765/ plsa.v2i0.4055. 